\title{
Cooperation With Evil: Its Contemporary Relevance
}

The Linacre Quarterly 2020, Vol. 87(I) 25-33

(C) Catholic Medical Association 2019 Article reuse guidelines: sagepub.com/journals-permissions DOI: 10.1 I 77/00243639|9885674 journals.sagepub.com/home/lqr

(S)AGE

\author{
Judith Lee Kissell, MA'
}

As conscience issues have multiplied in medicine, so has concern for what constitutes cooperation with evil. This article, published in 1995, lays out a framework for making those difficult decisions. Judith Lee Kissell was a Clinical Scholar in the Center for Clinical Bioethics at Georgetown University at the time of its initial publication. She has since retired from Creighton University and the Creighton Center for Health Policy and Ethics in 2013 . She has lectured, published and done research in bioethics in the United States, Europe and Australia. She currently volunteers for the Nebraska Department of Health regarding healthcare legislation.

\section{Introduction}

Many current public policy issues both exacerbate, and raise our consciousness of, the problem of how we account for our complicity in the world's evil. Pertinent to our purpose in this article are problems raised by the current debate on health issues. The inclusion of abortion coverage in a national health insurance plan and the role of the physician in public executions come to mind. Questions facing religious institutions and conscientious health-care providers in general, constitute an arena which should convince us of the importance of understanding the complex matter of lending ourselves to wrong-doing.

These problems, and others like them, accentuate the renewed relevance of Catholic moral theology's traditional treatment of the concept: cooperation-with-evil doctrine. Despite its relevance, despite the urgency of our understanding it well, the doctrine of cooperation-with-evil is seldom thoroughly and satisfactorily explored. Our purpose in this discussion is to show how we justify blame for complicit acts.

First, we frame the doctrine within the broader picture of complicity and second, we recast some of the conditions of the doctrine into a more comprehensible framework. Several factors contribute to confusion about cooperation doctrine. The first two relate to the more general concept of complicity.
One, the notion of the complicitous act is fraught with ambiguity. What is its nature? we must ask. What makes such an act culpable? Two, the very nature of the complicit act dictates that each complicit deed only analogously resembles other such deeds. For instance, acting as a lookout for a burglary and hiring a killer are both complicitous acts, but their point of comparison is obscure.

Moreover, we have the important factor of the connection which joins a given complicitous act with the harm/wrong to which it contributes. Whatever this connection is, while it resembles causality, it lacks causality's coherence. For example, the lookout's connection to a robbery is one of expediting. But we would describe the connection of the person who hires a killer to the murder as instigation. These connections, like the acts themselves, are also only analogous to the links present in other complicitous acts.

\footnotetext{
' Center for Clinical Bioethics, Georgetown University, Massachusetts, MA, USA

Corresponding Author:

Judith Lee Kissell, MA, Center for Clinical Bioethics, Georgetown University, Massachusetts, MA 19004, USA. Email: golder@cathmed.org
} 
Thus, although we can easily understand the rationale which allows a nurse to cooperate with an abortion - the case familiar to us from many texts we have difficulty expanding the notion to other cases. The precise the nature of the act, the exact character of the connection between the act and the harm/ wrong $^{1}$, make application of the concept difficult. A clarification of complicity itself will make cooperation-with-evil doctrine easier to understand.

Cooperation doctrine's third confusion-producing factor lies in the similarity of the doctrine to the principle of double effect. Writers often imply that the two principles are nearly identical. Such an identification, however, obscures cooperation doctrine and makes it less understandable. A clearheaded account requires that proper distinctions be made between the two concepts. In this article, we hope to shed light on the topic of cooperation-with-evil by addressing the confusions we have listed.

In Section II we lay down the characterizing features of complicit acts. We also discuss the analogous nature of complicit acts and its implications. In Section III, we focus on cooperation-with-evil doctrine - elucidating its contrast to the double effect principle and by highlighting certain key concepts which make the doctrine distinctive.

\section{A Conceptual Explanation of the Complicitous Offense}

\section{The Complicitous Act as "Non- violating" and Incomplete}

Our first objective is to set cooperation-with-evil doctrine within the context of complicity in general. For our purposes here, we discuss complicity as positive collaboration, that is, as a participative act on the part of an agent who knowingly and intentionally takes part in a harm/wrong perpetrated by another person. ${ }^{2}$ Positive collaboration also includes omissions to act when the agent's duty to prevent a harm/wrong clearly exists.

The complicit act has two philosophically interesting features. Complicity is by its nature incomplete. This means that we can only understand it in conjunction with the primary offense with which it is allied. Being incomplete does not in itself connote mitigation of culpability. The complicit act may be less blameworthy, but not necessarily. Nor does incompleteness imply that the accomplice's intention is less culpable from a subjective point of view. Thus for instance, we have Greek tragedy's classic case of complicity. Here Aegisthus' encouragement of Clytemnestra to murder her husband,
Agamemnon, is less odious than the murder itself. But Aegisthus' influence entails equal guilt, not less. So too, Clytemnestra may have failed to carry out the deed. But possible frustration of the act does not affect the subjective culpability of the accomplice's intention.

To deem the complicitous offense as incomplete simply means that we cannot give an account of Aegisthus' encouragement without Clytemnestra's killing, or her intended killing, of Agamemnon. As a corollary of being incomplete, complicitous conduct is "non-violating" in this precise sense: the conduct in itself violates no norms; its offensiveness resides solely in the circumstances which associate it to a primary offense. ${ }^{3} \mathrm{We}$ do not describe, and then prescribe, specific complicit acts - for instance, hiring a killer, providing a weapon, provoking anger, holding the victim down, and on and on. Such an enumeration would constitute a monumental task beyond the scope of any system of mortality.

\section{The Problem of Analogy and Connection}

Even armed with the notions of non-violation and incompleteness, we still find complicity to be an ambiguous concept. An important reason for this ambiguity lies with its analogous character. Complicit acts themselves, and the connections between these acts and the harm/ wrong they help to produce, have fundamental characteristics in common. However, their circumstances differ enormously. Yet, we can only warrant blame for the collaborative act in view of this connection. The connection itself might have one of a variety of descriptions: the accomplice might provide the weapon; he might encourage the killer; he might fail to warn the victim. Conversely, he might control the situation by instigating the offense and hiring the killer. In comparison to the primary offender's relatively forthright "causal" link to harm, the accomplice's connection is convoluted. Consequently, we have difficulty explaining exactly how widely differing acts can be complicit. We would be helped if the connection between the act and the harm were as straightforward $a<$; causality. We could then describe complicity as those acts which indirectly "cause" harm. Good reasons exist, however, for hesitating to use the terminology of causation.

The Jewish tradition of "no agency" addresses this problem. For one thing, the accomplice's act does not, by nature of its being incomplete, produce harm. For another, if we say the accomplice causes the harm/ wrong, it can only be through the primary agent. We would then have mitigated the moral 
accountability of that agent. For this reason, the Jewish tradition does not recognize "agency", in which one agent acts for another. According to the Jewish teaching, if Person $\mathrm{X}$ is hired by Person $\mathrm{Y}$ to kill someone, Person $\mathrm{X}$, the primary offender, bears sole responsibility. Person Y cannot cause him to commit murder.

Likewise, H.L.A. Hart and Tony Honore ${ }^{4}$ distinguish between complicity and casuality in dealing with accessory liability in Common Law. They argue that The general principle of the traditional doctrine [on causation 1 is that the free, deliberate and informed act or omission of a human being, intended to exploit the situation created by defendant, negatives causal connection (emphasis included). ${ }^{5}$ The next best solution for defining the required connection is to describe the general conditions under which the relationship between actions and harm/wrong result, and under which they are considered culpable. In this way the connection applies to a broad number of instances. Common Law refers to "aid" and "influence". 6

These terms - to which we might refer as "causelike" - suffice to describe cooperation-with-evil as well. They cover the broad and often ambiguous link between the harm/wrong and the accomplice's participation. The problem for complicity then, lies in understanding the nature of the complicitous act and in explaining the relationship between the harm/ wrong and the non-violating, incomplete act which merely contributes to harm/wrong. With grasp of these notions we can better understand the culpability which attaches to the act. We can justify blame.

This broad picture of complicity constitutes a context into which we can place cooperation-withevil doctrine. Cooperation doctrine comprises a special case of the collaborative complicit offense. We must now consider it in more detail.

\section{Complicity as Cooperation- With-Evil}

The problem of complicity has been with us for a very long time. An early statement regarding the concept appears in the writing of Tertullian when he admonishes the idol makers: Nay, you who make, that they may be able to be worshipped do worship. More are you to them than a priest, since it is by your means they have a priest; your diligence is their divinity (emphasis in original). ${ }^{1}$ Clearly Tertullian has a strong conviction about Christians who craft idols and build temples - theirs is an unacceptable collaboration with idolaters. But his potent statement fails to provide guidance beyond the specific case because it lacks a formula by which we could first, determine the conditions which constitute such an offence (such as we called for above) and second, make a judgment of guilt in relevantly similar instances. ${ }^{7}$

Thomas Aquinas in the twelfth century provides more guidance and rational structure when he explains the sinfulness of these same idol makers. ${ }^{8}$ Where Tertullian relies upon rhetoric to make his point, Aquinas makes use of a reasoning strategy. We now call this structure the doctrine of cooperation-with-evil, and it owes the careful conceptualization it has today to another theologian, Alphonsus Liguori. ${ }^{9}$ Aquinas, Liguori and subsequent theologians have developed a formula determining when the link between an agent, and a wrong to which he contributes, is culpable.

\section{The Description and Framework of Cooperation-with-Evil}

We begin by exploring the kind of cases which cooperation-with-evil doctrine addresses. Cooperation doctrine constitutes a special case of collaborative complicity. It functions as a conflict-resolving strategy, concerned with situations in which an agent's collaboration may or may not be justified. The agent becomes culpable when he cannot vindicate his collaboration according to the appropriate conditions.

Admittedly the doctrine owes much of its dynamic to the thinking behind the principle of double effect. Both address predicaments in which a refusal to have a connection with a wrong might seriously jeopardize the life or welfare of the morally conscientious agent or some other person. Cooperation doctrine however, is analogous to, but distinct from, the principle of double effect. It applies rather, to cases in which an agent might contribute to, rather than perform, a proscribed deed. We readily recognize as examples the classic cases of the nurse who aids in an illicit hysterectomy or the hospital which makes policy about such surgeries.

The doctrine's conditions include some, but not all of the criteria, which govern the principle of double effect. It makes particular use of the notions of intention and proportionate reasons for performing an act. However, two further conditions distinguish cooperation doctrine. The first - necessity - pertains to the degree to which the cooperating agent's act furthers the primary agent's act (or harm resulting from that act); to what degree the primary offense depends on the cooperating agent. How indispensable is the seller of guns, for example, to a murder? 
The second condition - proximity - addresses the similarity between the acts of the two agents: how close in description, and in effectiveness for achieving the objective of the primary offender's act, is the accomplice's act? Does the nurse's handing instruments to the surgeon, for instance, constitute a closer kind of participation than the orderly's delivering the patient to the operating room?

\section{The Considerations and Conditions of Cooperation-with-Evil Doctrine}

Cooperation in wrong or cooperation in harm? Before we discuss the conditions of the doctrine, we need to make a point about the nature of cooperation doctrine, which allows us to expand its applicability. Theologians often describe cooperation-with-evil in terms of the cooperating agent's relationship to the will of the primary offender. ${ }^{10}$ However, we find this notion difficult to defend consistently. Common sense suggests that the cooperating agent cannot sway the primary agent's will without the primary agent's direct awareness. Yet the nurse may never come into contact with the surgeon who performs the surgery. Furthermore, the surgeon's intention to perform the surgery gets him to the operating room. Even if once there he finds no personnel willing to perform the necessary preparatory tasks, the surgeon's will, or intent, may remain, though frustrated. ${ }^{11}$ If the cooperating agent influences only the primary agent's will, the "cooperation" pertains to the primary offender's subjective immoral act rather than to an objectively wrong state of affairs or to the harm which might affect a third party.

This idea narrows the application of cooperation doctrine. The question of influencing the primary offender's will is complicated, for example, by the case of Tertullian and the idol makers. We could argue that while paying homage to their deities is objectively wrong (in the eyes of the Christian Church), the idol worshipers' act is not subjectively culpable. In that instance, the idol makers' influence upon the idolaters' wills does not further wrongdoing in any subjective sense. It simply aids or facilitates an offensive state of affairs.

Edmund Pellegrino, ${ }^{12}$ raises a more pertinent, and more interesting point, in applying cooperation doctrine to the obligations of the institutional physician, piquing thereby the issue of "cooperating-withharm". His account implies that we should not limit the doctrine to the cooperating agent's effect on the primary offender's will, nor to his contribution to wrongdoing. We might well speak instead of the cooperating agent's contribution to harm. He makes compelling use of the doctrine to determine the liability of the prison or military physician whose obligation to his institution conflicts with his obligation to his patient.

Here Pellegrino goes beyond the dictates of the natural law to address the special obligations of the medical profession. He considers the duty of the prison physician who participates in an execution, ${ }^{13}$ or the military physician who declares a soldier fit to return to battle. Unless we understand the debate to be about the legitimacy of war or capital punishment in these cases, the physician neither sways the will of the primary offender - the institution - to commit, nor contributes to, wrong-doing. Sending the patient to war or to be executed harms the patient but does not wrong him.

The physician does not influence the will of the institution so much as contribute to harming the patient. Thus the doctrine affords us a broader view of complicity when it extends to the cooperating agent's participation in harming third parties.

The conditions, and considerations, for culpable cooperation with harm/wrong. The conditions which constitute the doctrine of cooperation-with-evil are familiar. In considering them therefore, we shall concentrate only on those aspects of the doctrine which are frequently confused with the principle of double effect. Furthermore, we shall consider the conditions in their positive light. In other words, though these conditions are often described as justifying cooperation, we shall examine them insofar as they justify blame. As we have pointed out, some moralists try to draw an exact parallel between the two doctrines, while they in fact differ importantly from one another.

The nature of the act. The cooperating agent commits a non-violating and incomplete act. That is, the act is culpable but not because some precept prohibits it and not because it suffices to produce harm. We can easily see that the cooperating offense is both non-violating and incomplete. Were this act itself prohibited and capable of producing harm/ wrong, the accomplice would be a primary offender rather than an accomplice, and we would not need to appeal to cooperation doctrine to explain its wrongness.

Here we find our first important dissimilarity with the principle of double effect. Where the double effect principle depends importantly on the "intrinsic wrongness" of the agent's act, ${ }^{14}$ that condition becomes irrelevant in cooperation doctrine. The act itself is wrong only in its circumstances. One factor 
of its incompleteness is that its wrongness lies somewhere other than its being prohibited by a norm.

We look to the deed of the primary offender as the source of liability for the cooperating agent in this sense: the collaborator's act is (objectively) wrong because the primary offender's act is (objectively) wrong. As non-violating and incomplete, the wrongness of the cooperating act itself lies only in its circumstances. Its wrongness lies somewhere other than its being prohibited by a norm or its producing harm.

"Formal" and "material" cooperation. The conditions of formal and material cooperation are likewise familiar to us. This condition more closely resembles the principle of double effect. An act of cooperation is culpable when the agent cooperates "formally" with the primary offender. Formal cooperation, which is always prohibited, consists in the agent's identifying with the will and intent of the primary offender. The cooperating agent is also sometimes culpable when he participates materially and proximately.

Here we have the first appearance of the proximity condition which distinguishes cooperation doctrine. In this latter case, the agent's act influences or aids the primary offender though he does not identify with the will and intent of the primary offender. However, his act might so closely resemble the primary offense that we would have difficulty in establishing its being non-violating and incomplete or insufficient to accomplish the harm; we could neither explain how the cooperating act differs relevantly from the prohibited act nor how the agent failed to intend the wrong. ${ }^{15}$ The more closely the accomplice's act resembles that of the primary offender, the more likely it is to be culpable.

A high degree of proximity requires that the reason for cooperating in the harm/ wrong be very important. We agree therefore with Grisez ${ }^{16}$ and O'Donnell $^{17}$ about the meaninglessness of the distinction between the immediate material act and the primary offense as illustrated in the case of the assisting surgeon, and we concur that such acts require no analysis in terms of cooperation doctrine.

Because the acts in question would lack the component of being addenda, they resemble those described in the law as "conspiracy" in which each participant is a co-agent and equally culpable. Because they so closely resemble the primary offense, to maintain that they were indirectly intended would be inconsequential. The question of justification for cooperation arises then, only in mediate material cooperation which we could describe as influencing and/ or aiding.

Proportionate reason. We can state the proportionate reasons condition like this: the cooperating agent's contribution to a primary offense would be culpable if his reasons for cooperation were disproportionate to the wrong the primary offender commits or the harm he perpetrates. Because of the non-violating nature of the cooperating agent's act, this condition governs cooperation doctrine, as we shall see. Further, the complexity of the proportionate reasons condition, together with its resemblance to that found in double effect doctrine, prompt us to ask these four questions: first, must we become embroiled in the debate over proportion found in double effect doctrine? Second, does the term "proportionate" involve us in problems of the weighing of incommensurate values and other difficulties inherent in consequentialist formulas? Third, what factors must the agent juggle in establishing proportionality? Fourth, how does the agent conduct this juggling? Our first question concerns the proportionalism debate in double effect doctrine.

We find the proportionate reasons condition controversial within that doctrine because, there, proportionality seems to impact the very nature of moral reasoning. This impact occurs because the doctrine evaluates an act and determines whether or not this act does in fact violate a norm. On one interpretation, if this condition governs double effect doctrine, its moral reasoning seems to be fundamentally consequentialist. ${ }^{18}$ To claim, on the other hand, that this condition governs cooperation doctrine, does not entangle us in this debate. Proportionate reasons become the focal issue in cooperation-with-evil precisely because the cooperating agent performs neither an "intrinsically" nor "deontologically" bad, (i.e., morally bad) nor prima facie bad, act. ${ }^{19}$

If the cooperating agent's acts were bad in these ways, we would not require cooperation doctrine to analyze them. The act in question violates no norm nor value, even on its face. It presents a problem because, while non-violating, it still involves, through its circumstances, some ambiguous relationship to someone else's act. Granted the nature of the act, attention focuses on the circumstances surrounding it. Our second question deals with the problems of incommensurate values and their comparison. If we attempt to compare values as a way to evaluate the cooperating act, we find ourselves implicated in problems inherent in consequentialism. To some extent, we have here a language problem. 
The traditional terminology of "proportion" connotes the activity of quantatively weighing and calculating, etc., of values or goods. Alternatively, it could suggest finance-type transactions of exchanging one value or good in fair exchange for another deemed equal in worth. The problems of determining which criterion of value to use, or how to apply this criterion to such disparate goods, then faces us. In any sense, we find commensurability perplexing. ${ }^{20}$ We cannot compare the quality of life for the unemployed nurse to the life of the fetus. Other problems seem also to exist in determining proportion if we understand it quantitatively. An alternative view of how we arrive at proportionate reasons eliminates these difficulties. We might regard the question as one demanding - not calculation, such that the better course of action outweighs its alternatives by some standard of measurement - but prudence. ${ }^{21}$

In the first place, we have already established that, since the cooperating act violates no norm or value, our assessment of it concerns the circumstances. We might rather express the condition of proportionate reasons like this: we censure the cooperating act when a prudential judgment, which considers the disvalue of the primary offense, the situation of the agent and the circumstances surrounding his contribution to evil, deems the act as inappropriate. The importance of this articulation lies in the role of prudence for judging between incommensurate values by reason of the cogent circumstances.

Circumstances might justify the physician's role in declaring a patient fit to return to battle, in Pellegrino's instance. Prudence evaluates these circumstances. We may now ask our third question: what factors must prudence juggle in establishing a proportionate reason? The intricacy and ambiguity of the act itself, and of its circumstances, make the establishment of a proportionate reason a convoluted process. The agent must evaluate an act, which though non-violating, somehow contributes to a moral wrong.

The proportionate reason then takes into account the gravity of the primary offense in relation to the benefit to the cooperating agent. We judge the benefit itself in light of the necessity and proximity of the agent's contribution to the primary wrong. That is, the reasons themselves must be graver and the benefit more substantial, the more necessary is the cooperating agent's contribution, or the closer is his contribution, to the primary offense. We thus find ourselves in a labyrinth of considerations, and we need a unified and discriminating comprehension to deal with it. The ability to unify these disparate issues uniquely qualifies prudence for the task.

Our fourth question asks how the agent juggles these factors or how prudence operates in this situation? Prudence constitutes that ability to grasp as an integrated whole the intricate components of a situation and make a judgment about the right thing to do. We ordinarily describe the prudent agent like this: first, he possesses a keen insight into the value or norm at stake. He then "casts about from point to point", in the words of Aquinas, among the circumstances of the concrete situation, in light of the relevant value or norm, to determine the appropriate action. Thus prudent judgment always occurs within the objective restraints of the moral tradition, making the judgment "publicly intelligible". ${ }^{22}$ Furthermore, the agent acts from a position of commitment to these norms and values. He is a generally virtuous person whose insight into the right thing to do stems from his devotion to his final end. ${ }^{23}$

We attribute the effectiveness of the prudent agent to his aptitude for circumstances. With his eye - and heart - firmly fixed on the relevant norms and values, he possesses flair and imagination for determining what to do in the concrete situation. We might say he describes well: his competence consists in his ability to thoroughly and sensitively describe situations, taking into account all and only those circumstances relevant to the case; he manifests a moral awareness as well as a wide knowledge of human nature. Robert Henle ${ }^{24}$ draws the analogy between prudence and the ability to understand a political cartoon. This apt analogy emphasizes the importance of the agent's affinity to the context, ${ }^{25}$ his grasp of the situation, his familiarity with the setting and his ability to be imaginative.

Ultimately, prudence coordinates the particulars within the broader picture and says: act like this in these circumstances. What then, does prudence look like in respect to cooperation-with-evil?

The use of prudence within any casuistic framework - such as the doctrine of double effect - alters its character. Its use with the doctrine of cooperation-with-evil changes it yet more. In the casuistic framework, the first departure from the ordinary use is this: casuistry requires prudence for determining culpability both as a teaching and juridical instrument. In other words, we use cooperation doctrine to distinguish between permissible and impermissible acts, not of ourselves, but of others. For instance, a medical ethics course might address the circumstances under which an institutional (prison or military) physician functions. A confessor or counselor may use the doctrine to determine the 
degree of culpability for someone's participation in an illicit act.

In both these instances, the character and virtue of the cooperating agent, as it relates to the prudential judgment, may not be in question. Rather, the character and virtue of the teacher or judge might be at issue in their exercise of prudence. Moreover, in casuistic practice, prudence has additional tasks to perform. Casuistry usually requires that prudence place the act within the relevant taxonomy of cases. ${ }^{26}$

But in cooperation doctrine, while the primary offense may fall into some such taxonomy, the cooperating act itself does not. It is a non-violating act. While we have only a given number of ways to directly violate norms, we have an unlimited number of ways of indirectly participating in their infringement. In this case, the prudent agent's keen insight into norms and values functions in a peculiar way.

The role of prudence is to perceive the connection between the moral evil, the non-violating act and its circumstances. We usually do not need such insight for the immediate and blatant offense. Further, the very nature of casuistic reasoning in these cases means that each situation is only analogous to the others because so many, and such varied, possibilities for collaboration exist. The ability of prudence to detect and articulate the ambiguous and analogous relationship is critical.

Prudence next sorts through the benefit to the agent - a seemingly simple task. However, the agent must view this benefit in light of the necessity and proximity of his participation. Determining proportionate reasons, in other words, means grasping the ambiguous relationship between the primary evil and the cooperating act, and then juggling the evil of the primary offense and the benefit to the cooperating agent in light of two other issues - the necessity and the proximity of his contribution.

With the exception of the primary evil, all these issues - the benefit to the agent and the necessity and proximity of his contribution - plus some others, fall under the rubric of circumstance. Prudence grasps and evaluates this complex situation. We now turn to the necessity and proximity of the cooperating agent's action. iv. Necessity and proximity. The necessity and proximity of the cooperating act govern the proportionate reasons condition in warranting justification or blame for an action. The necessity condition tells us what relationship exists between the acts of two or more persons.

We have already suggested that the cooperating act is incomplete. The necessity condition reaffirms this idea but in reverse. In addition, the term "necessity" suggests a cause-like relationship. It tells us how much the cooperating agent's act expedites that of the primary offender. The more necessary the agent's contribution to the primary wrong, the more serious must be his reasons for cooperating if he is to escape culpability.

The limiting case of the necessity requirement determines whether the wrong would occur but for the aid of influence of the accomplice. This requirement, while acknowledging the incompleteness of the cooperating act, supposes that it constitutes a more or less essential part of the primary offense. We measure necessity in this case, by degree and circumstance.

How much does the primary offender need the assistance of the cooperating agent? Circumstances often determine degrees of necessity. For instance, if only one nurse lives in a certain village, his assistance to any medical procedure is more necessary than that of nurses in large cities. The agent depends on prudence to consider such circumstances and to determine the degree of his necessity to the primary offense, and more importantly, whether his reasons for participating and the degree of necessity together, outweigh the primary wrong.

We have recently learned of experiments on radiation being carried out upon unsuspecting victims, by the United States government. ${ }^{27}$ If Person $\mathrm{X}$ is the sole record-keeper and corporate memory for the radiation experimentation records, her reason for not coming forward must be very grave indeed. The occurrence or non-occurrence of the concealment of the records depends solely, or heavily, on her. Other circumstances affect the question of her necessity. To what degree I would she recognize relevant data? Does her position give her credibility? The problem of the proportionate reasons remains, but Person X's necessity becomes clearer.

We have greater difficulty conceptualizing proximity. The proximity condition tells us how much the cooperating agent's act resembles the primary wrong in achieving its purpose. The more closely his contribution coincides with the primary wrong, the more serious must be his reasons for cooperating. Immediate material cooperation constitutes the penultimate case and the proscribed deed itself, the limiting case.

The inconsistencies which result from the long evolution of the principle of double effect and cooperation doctrine obstruct our ability to gain a comprehensive and satisfactory grasp of proximity. We might regard contributions to a proscribed deed as a continuum. Without prudence, such a view might imply a certain physicalism by which the act itself, apart from the human elements of knowledge and 
intention, possesses not only moral value, but quantifiable moral value. The prudent agent however, evaluates his contribution to the wrongful act and the degree to which it approaches the wrongfulness of the proscribed act itself. Prudence views the act as closer to or farther from the violating and complete nature of the primary offense. The agent's reason for participating in the wrong must be greater as his contribution moves up the scale toward unequivocal wrong-doing.

Here again, our operative concepts fit only approximately, sometimes better, sometimes worse. The prudent agent is able to unify these approximate and confusing elements of necessity, proximity and proportionate reasons. Furthermore, he discerns from their perhaps unique configuration, the proper, and the loving, thing to do. This description of a moral act indeed seems strange, and like all analogies, this one clarifies some difficulties while obscuring others. The clerk who admits a pregnant woman into an abortion clinic plays a more remote role than the anesthesiologist who assists with the procedure. Proximity in time and place, which explain the immediacy of the anesthesiologist's contribution, seems to help explain proximity.

This explanation fails though, to account for the case of the administrator of a group of hospitals who must decide about certain controversial or ambiguous policy matters. In this case the cooperating agent, the administrator, might reside in a city at a thousand miles distance and may make decisions a month in advance. We can only describe proximity analogously, for we seem to grasp the concept intuitively rather than conceptually. Each application of proximity constitutes merely an approximation of a model. The wide variety of situations to which these conditions must apply, the difficulty in specifying the necessity and proximity conditions and the commensurability problem which accompanies the proportionate reasons condition itself, all serve to complicate the doctrine of cooperation-with-evil.

We have seen that an agent, or a third party, evaluates the agent's contribution to a wrong by first ascertaining whether the agent joins his intention formally - to that of the primary offender in willing the wrong of the offense. Next, his reasons for participating in the wrong must be evaluated in view of the degree to which his contribution is necessary and the degree to which his contributing act approximates the primary offense. The agent must then make the determination about whether these latter three conditions together are proportionate to the wrong committed by the primary agent.
If any of these conditions is not met and the agent knows his cooperation to be unwarranted, but he chooses to make his contribution nonetheless, blame for collaboration is justified.

\section{Conclusion}

Our view of cooperation-with-evil now appears within the general framework of complicity. An understanding of complicitous acts as incomplete and nonviolating helps us to understand the ambiguity of collaboration in others' wrongdoing. The acts themselves, and the links associating accomplices to the harm/wrong in which they participate, belong to a kind of family - joined by analogy. We cannot say that an accomplice causes harm/wrong, but we may frame his participation as aiding and influencing.

With this new understanding of cooperationwith-evil doctrine as part of the broader concept of complicity, we must consider the doctrine itself. Although cooperation doctrine resembles aspects of the principle of double effect, it is distinct from it. Cooperation doctrine deals with non-violating acts, insufficient of themselves to produce harm/wrong. The doctrine centers around proportionate reasons which must be balanced with the necessity and the proximity of the accomplice's participation.

Cooperation doctrine can be expanded to explain cooperation with harm rather than only with wrongdoing. With this more in-depth analysis behind us, we approach once again the possibilities of lending ourselves to wrong-doing in our world. We consider the problems present in health care, in professional ethics, in public policy, with sharpened tools for moral diagnosis and for understanding.

\section{Declaration of Conflicting Interests}

The author(s) declared no potential conflicts of interest with respect to the research, authorship, and/or publication of this article.

\section{Funding}

The author(s) received no financial support for the research, authorship, and/or publication of this article.

\section{References}

1. We refer in this article to harm/ wrong for reasons which become apparent later. Simply put, harm seems to have connotations of objectivity, while wrong seems to be more Subjective.

2. We distinguish complicity as positive collaboration from complicity as tolerating evil. Supporting racist 
employment policies, for instance might constitute a case of tolerating evil, but blame for such toleration is more difficult to justify.

3. A primary offense in contrast, in itself violates a norm killing, for instance - and, according to the principle of double effect, may be allowed only by reason of its circumstances.

4. H.L.A. Hart and Tony Honor . Causation in the Law. Oxford: Clarendon Press. 2nd edition. 1985.

5. Hart Honor , Causation, p. 136

6. See Smith in general; Fletcher. Rethinking, 6400; and Kadish, Complicity, 343.

7. Tertullian. On idolatry. Ante-Nicene Fathers. Alexander Roberts, D.O. and James Donaldson, LL.D. Grand Rapids, MI: Wm. B. Eerdmans Publishing Co. 1957. 64.

8. Thomas Aquinas. Summa Theologica. London: Blackfriars and McGraw-Hili Book Company. 1964. 2a2ae. 169, 2 (hereafter ST).

9. Charles E. Curran. Cooperation: Toward a Revision of the Concept and its Application. Linacre Quanerly. 41(3). 1974. 152-167.

10. See Charles E. Curran, Cooperation. E.J. Hayes, P.J. Hayes, \& E.D. Kelly. Moral Principles of Nursing. New York: Macmillan. 1964.

11. Charles J. McFadden. Medical Ethics. Philadelphia: F. A. Davis Co. 1961; Henry Davis, SJ. Moral and Pastoral Theology. New York: Sheed and Ward. 1952. 44 Linacre Quarterly II. Some might claim that the influence consists in the scandal the cooperating agent provides. But the notion of scandal, one, begs the Question and two, constitutes a separate category of offense, one which exceeds our explanation.

12. Pellegrino. Cooperation, Moral Complicity, and Moral Distance: the Ethics of Forensic, Penal, and Military Medicine. InternatioTUlI Journal of Law and Ethics. Vol. II. 1993. 371-91.

13. The AMA has spoken out recently censuring physician participation in executions.

14. We are thereby alleviated from joining the debate about the possibility of "intrinsically wrong" acts.

15. We might take the example of the assisting surgeon in an abortion whose actions so patently parallel the principle surgeon's that the two are virtually alike. We agree therefore with Germain Grisez (Christian Moral Principles. Chicago: Franciscan Herald Press.) and Thomas O'Donnell (Morals and Medicine. Westminster M.D.: The Newman Press. 1956), about the meaninglessness of the distinction between the immediate material act and the primary offense as illustrated in this case. We concur that such acts require no analysis. Because they so closely resemble the primary offense, to maintain that they were indirectly intended in the specific sense would be inconsequential. The Question of justification for cooperation arises then, only in mediate material cooperation which we could describe as influencing and/ or aiding.
16. Grisez, Christian Moral Principles.

17. O'Donnell, Morals and Medicine.

18. Richard McCormick denies that his proportional ism would make him a consequentialist. However, some interpret him in this way (Doing Evil to Achieve Good).

19. We assume here that the agent does not intend the wrong of the primary offense. We can see here the value of describing the cooperating act as nonviolating and incomplete in order to distinguish it further from the "morally neutral" act of double effect. The morally neutral act can, by itself, produce harm/ wrong.

20. Within the doctrine of double effect the Question of proportionality as having possible consequentialist impact is important. The doctrine is designed to work within a deontological framework which eschews consequences as a measure of moral worth. Even if this or some other interpretation of proportion, such as McCormick's (see his Doing Evil to Achieve Good) constitutes a problem for double effect doctrine, the situation differs for cooperation-with-evil. In this latter case, we already concede the primary offender's act to be wrong. Whether we censure that act wrong for deontological or consequentialist reasons does not matter. At issue is the culpability of a cooperating act which merely contributes to the already condemned wrong.

21. I have recast the proportionate reasons condition in terms of prudence at the suggestion of Kevin Wildes, SJ.

22. William C. Spohn, SJ. The reasoning heart: An American Approach to Christian Discernment. Theological Studies. 44: I. 1983. 30-52.

23. The final end distinguishes Aristotelian phronesis from scholastic prudence. For cooperation doctrine of course, this issue is theological and not within the scope of this paper.

24. Robert Henle, SJ. Prudence and insight in moral and legal decisions. The role and responsibility of the moral philosopher. Proceedings of the American Catholic Philosophical Association. Washington, DC: The Catholic University of America. 1983.

25. Hart's notion of the "internal aspect" of rules could be applied to the prudent agent. Hart suggests that those who subscribe to norms or values penetrate their meaning in a way that differs from that of the mere observer. Surely the prudent agent must view the norms or values in the way Hart describes (The Concept of Law Oxford: Clarendon Press. 1986, especially 97-120.)

26. Albert R. Jonsen and Stephen J. Toulmin. The Abuse of Casuistry. Berkeley: University of Chicago Press. 1988.

27. Associated Press. More than 5,000 Exposed to Radiation in Experiments. Washington Post April 6, 1994. A17. 